\title{
BMJ Open Systematic review of interventions targeting sickness absence among pregnant women in healthcare settings and workplaces
}

\author{
Pernille Pedersen, ${ }^{1}$ Merete Labriola, ${ }^{2}$ Claus Vinther Nielsen, ${ }^{2}$ \\ Rikke Damkjær Maimburg, ${ }^{3,4}$ Ellen Aagaard Nohr, ${ }^{5}$ Anne-Mette Momsen ${ }^{1}$
}

To cite: Pedersen P, Labriola M, Nielsen CV, et al. Systematic review of interventions targeting sickness absence among pregnant women in healthcare settings and workplaces. BMJ Open 2018;8:e024032. doi:10.1136/ bmjopen-2018-024032

- Prepublication history and additional material for this paper are available online. To view these files, please visit the journal online (http://dx.doi. org/10.1136/bmjopen-2018024032).

Received 9 May 2018

Revised 14 September 2018 Accepted 18 September 2018

Check for updates

(C) Author(s) (or their employer(s)) 2018. Re-use permitted under CC BY-NC. No commercial re-use. See rights and permissions. Published by BMJ.

For numbered affiliations see end of article.

Correspondence to Dr Anne-Mette Momsen; anne-mette.momsen@rm.dk

\section{ABSTRACT}

Objectives The high rate of sickness absence from work during pregnancy is recognised as a problem, and may be higher than necessary from a health perspective. The aim was to evaluate the effectiveness of interventions in healthcare settings and workplaces targeting sickness absence among pregnant women.

Methods Studies were eligible if they included pregnant women participating in any intervention in healthcare settings or workplaces. The outcome was length of sickness absence in days or number of episodes. Study design had to be either randomised controlled trials (RCTs) or quasi-experimental studies. The search for studies was conducted in PubMed, Scopus, CINAHL, PsycINF0, ClinicalTrials.gov and WHO trial registry. Risk of bias was assessed by the Joanna Briggs Institute standardised quality assessment instrument.

Results A total of nine studies were quality assessed and of these, four were excluded due to insufficient methodological quality. Five RCTs conducted in healthcare settings in Sweden and Norway were included. Due to heterogeneity, meta-analysis was not performed. Two RCTs examined complementary and alternative medicine and three RCTs the effect of physical exercise. In general, the frequency of women on sickness absence was lower in the intervention groups than the control groups, however, only among pregnant women who participated in a 12week exercise programme, the frequency was significantly lower ( $22 \%$ vs $30 \%, p=0.04)$.

Conclusion The evidence of interventions targeting sickness absence among pregnant women in healthcare settings is sparse, and no studies were conducted at workplaces. Future interventions including physical activity provided in collaboration with healthcare settings and workplaces are requested. Studies should measure sickness absence based on valid methods, measure compliance to the intervention and provide transparency of statistical methods.

PROSPERO registration number CRD42018084802.

\section{INTRODUCTION}

Pregnant women may experience bodily changes as disabling and they consequently may be on sick leave from work. ${ }^{1-3}$ Sickness
Strengths and limitations of this study

- This review aimed to evaluate the effectiveness of interventions carried out in either healthcare settings or workplaces, and a quality assessment was performed using a standardised method. However, no studies conducted at workplaces were found.

- The five studies included were all conducted in Sweden and Norway; only one study of a 12-week exercise programme demonstrated a significantly reduced sickness absence frequency among pregnant women.

- The studies may be underpowered and not able to detect a difference in sickness absence.

- Future interventions need to explore the effect of physical activity on work maintenance, and be carried out in collaboration with healthcare settings and workplaces.

- Sickness absence as well as compliance with the intervention should be measured based on valid methods.

absence due to pregnancy may be higher than necessary from a health perspective ${ }^{4-6}$ and it is argued that pregnancy is being medicalised. $^{7}$ The duration of sickness absence may be reduced by interventions aiming at work maintenance for pregnant women, thus, it is of importance to explore such interventions conducted in healthcare settings and workplaces.

In Scandinavia, the rate of sickness absence among pregnant women is high compared with non-pregnant women. ${ }^{7-12}$ Thus, the average sickness absence is 8.5 days per year for all Danish employees ${ }^{13}$ compared with 48 days among pregnant women. ${ }^{14}$ In Norway, three out of four pregnant women were absent due to sickness for a median duration of 8 weeks. ${ }^{15}$ The average sickness absence during pregnancy has increased over the last decades. ${ }^{10} 16-18$ 
According to the literature, the main reasons for sickness absence during pregnancy are health related, for example, nausea/vomiting, fatigue, sleep disturbances, bleeding, pelvic pain and low back pain. ${ }^{12} 1^{19-21}$ Especially low back pain is frequent and increases the rate of sickness absence during pregnancy. ${ }^{22}$ Low back pain may also have impact on future work ability if rehabilitation is insufficient as the rate of relapse is high. ${ }^{22} 23$

General and health-related risk factors for sickness absence include multiparity, age, educational level, use of reproductive therapy, back pain, maternal weight and smoking habits. ${ }^{11} 16{ }^{1724-28}$ Physical activity on the other hand is associated with a lower risk of absence from work during pregnancy, ${ }^{24}{ }^{25}$ maybe because it reduce pain and disability. ${ }^{22}$ Moreover, high maternal weight is a risk factor for low back pelvic pain. ${ }^{24}$ Thus, there seems to be a pathway from high maternal weight through low level of physical activity to sick leave during pregnancy. Pregnant women are therefore recommended to continue physical activity by healthcare professionals. ${ }^{29}$ Work-related risk factors include previous sickness absence, low job control, lifting, night or shift work, ${ }^{7}$ working in standing position and high job strain. ${ }^{30}$ However, except for high levels of exposure, such as working in night shift, $>40$ hours/week, lifting $>100 \mathrm{~kg} /$ day, standing $>6$ hours/day, recent reviews do not provide strong evidence for mandatory restrictions of occupational factors, as risk of miscarriage and low birth weight are only moderately elevated..$^{31-33}$ Thus, there is no reason to believe that common workplace exposures constitute a high risk for pregnant women. ${ }^{29}$

Moreover, job adjustment has been found to reduce sickness absence, but only few pregnant women obtain the needed adjustment. ${ }^{28} 34$

Sickness certificates may be needed if adjustments are not possible, for example, in hazardous jobs involving chemical procedures or biological risks. However, studies found that only $0.5 \%-5 \%$ of sickness certificates related to possible teratogenic effects. ${ }^{2135}$

Sickness certificates are issued based on health-related reasons. However, medical explanations may not be the main reason for sickness absence during pregnancy. A study found that three out of four pregnant women on sickness absence rated their health as good or excellent. ${ }^{36}$ Moreover, comparison of sick-listed to not sick-listed pregnant women has not shown differences in either mode of delivery or birth weight. ${ }^{18}{ }^{36}$ Thus, sickness absence may be a complex social phenomenon due to changes in attitudes towards the naturally occurring pregnancy discomforts as well as inexpedient coping strategies among pregnant women. ${ }^{19}{ }^{2037-39}$ Physicians might find it difficult to establish a medical diagnosis to support a sickness certificate and find themselves in a dilemma between being the woman's confidante and preventing unnecessary sickness absence. ${ }^{4-6}$ Legislation and compensation rules vary across countries resulting in different rates of sickness absence. ${ }^{40}$ Thus, associations are found between higher social benefits and higher rates of sickness absence registered during pregnancy. ${ }^{36} 37$
Sickness absence during pregnancy has consequences for both the pregnant women and society. At the individual level, the consequences are loss of possibilities for a salary increase and promotions, and it may result in a contract not being renewed. ${ }^{41}$ Moreover, long-term sickness absence is a predictor for future sickness absence and for receiving disability pension 8 years after child birth. ${ }^{25}$ For workplaces and society, sickness absence results in considerable costs due to reduced productivity; pregnancy-related sickness absence constituted around 4000 full-time positions corresponding to an annual cost of Kr1.4 billion. ${ }^{14}$ Moreover, employers may become reluctant to employing women of childbearing age. ${ }^{21} 41$

A literature review exploring pregnancy at workplaces recommends an improvement of the workplace conditions, for example, social support and a proactive approach. ${ }^{33}$ In order to sustain the ability to work for pregnant women recommendations are made to support a healthy work environment by eliminating risks and hazards. ${ }^{42}{ }^{43}$ Several current laws within the USA, Canada, the UK and the European Union (EU) are in force to delineate the rights of pregnant women. ${ }^{33}$ However, an initial search found only few interventions conducted in healthcare settings to reduce sickness absence; the studies were of low quality and results were inconclusive. ${ }^{445}$ The literature illustrates the potential for preventive initiatives in both healthcare settings and workplaces among pregnant women.

A search in the databases PROSPERO, PubMed, the Cochrane Library and the JBI Database of Systematic Reviews and Implementation Reports did not result in retrieving any systematic reviews or protocols on sickness absence among pregnant women. A Cochrane review was found on interventions preventing low back and pelvic pain, and whether treatments decreased the rate of sickness absence, but it focused on randomised controlled trials (RCTs) in prenatal care only. ${ }^{22}$

Thus, conducting this systematic review is an important contribution to the scientific literature in order to evaluate the effectiveness of interventions to reduce sickness absence in pregnant women in either healthcare settings or workplaces.

Results from this systematic review may contribute to developing an evidence-based intervention by integrating factors, processes and stakeholders relevant for preventive initiatives among pregnant women.

\section{Objectives}

This systematic review aimed to evaluate the effectiveness of interventions in healthcare settings and workplaces targeting sickness absence among pregnant women.

\section{METHODS}

\section{Patient and public involvement}

Patients were not involved in this review.

The electronic databases PubMed, Scopus, CINAHL, PsycINFO, as well as ClinicalTrial.gov and WHO trial 
registry were searched for published and unpublished studies, respectively.

A three-step search strategy was used ${ }^{46}$ with an initial limited search of PubMed followed by an analysis of the words contained in the title, abstract and index terms. A second search using all identified keywords and index terms was then performed. Finally, the reference lists of all identified studies were searched in order to find additional relevant studies.

Studies published in English, Danish, Swedish or Norwegian were included. As the initial search revealed that several studies were published between 1980 and 1990, the databases were searched from January 1980 to April 2017.

The following terms were used for the population: pregnant women, pregnancy, gravidity, gestational, child birth, peripartum and perinatal period. For the intervention: rehabilitation, vocational rehabilitation, occupational rehabilitation, intervention, general practitioner, maternal health services, maternal care, perinatal care, antenatal care and workplace intervention. For the outcome: sick leave, sickness absence, return to work, absenteeism, recovery of function, work disability, work capacity evaluation, work retention, health status, occupational diseases, medical leave and medical certificate (see online supplementary appendix A for search strategy).

\section{Criteria for included studies}

\section{Population}

The population included pregnant women at any gestational age. There were no restrictions based on sociodemographic factors such as age, ethnicity, parity, socioeconomic factors or health-related factors. The population included pregnant women employed in private or public workplaces in all types of work.

\section{Intervention}

The review included any intervention targeted at pregnant women. Intervention was defined as any initiative to retain pregnant women. The review compared the effectiveness of interventions carried out in all kinds of workplace settings (workplace or vocational rehabilitation initiatives) or healthcare settings (antenatal care, maternal care services or consultations by general practitioners or midwives). Studies were included regardless of the duration and intensity of the intervention.

\section{Studies}

The review included peer-reviewed published and unpublished studies. Study designs included RCTs and quasi-experimental studies with any comparator groups (eg, care as usual, no treatment, second intervention) in order to assess the effectiveness of the interventions.

\section{Outcomes}

Only studies assessing sickness absence or absenteeism during pregnancy were included. The occurrence of sickness absence during pregnancy was measured as number of sickness absence episodes and/or length of absence in days/weeks. ${ }^{47}$

\section{Selection of studies, risk of bias assessment and data extraction}

Two reviewers (PP and A-MHM) independently selected studies based on the inclusion criteria. Both reviewers screened the title and abstract of all eligible studies followed by a full-text screening of the selected studies. Any disagreement about selection, assessment and data extraction in included studies would be solved through discussion or by involving a third reviewer.

Studies selected for retrieval were assessed prior to inclusion for methodological validity by the two reviewers independently using a standardised critical appraisal instruments from the Joanna Briggs Institute. ${ }^{48}$ Studies assessed as being of insufficient methodological quality were excluded. Decision rules to be fulfilled for RCTs were all criteria except blinding, while for quasi-experimental studies, they were all criteria except the one concerning multiple measurements of the outcome.

The guidelines of Preferred Reporting Items for Systematic Reviews and Meta-Analyses were followed. ${ }^{49}$

All results were subject to double data entry. The extracted data included specific details regarding the study, settings, participants, description of the interventions, comparators, duration, length of follow-up and outcome measures of significance to the review objective.

The authors of the included studies were contacted to request any missing data for clarifying data.

If possible the objective was to estimate a summary average of the effect of the interventions concerning the number of days of sickness absence by use of the random-effect model. The improvement was defined as a decrease in sickness absence days at follow-up.

\section{RESULTS}

\section{Available evidence}

The systematic search identified 1243 potential studies (figure 1), of which nine were quality assessed (table 1). The five included studies were all RCTs from the Scandinavian countries including a single comparison group. ${ }^{50-54}$

Table 2 summarises the characteristics and results of the included studies.

A total of four studies were of insufficient methodological quality and thus excluded, ${ }^{44} 45556$ mainly because allocation to treatment groups was not concealed, follow-up was incomplete, and the statistic test applied was insufficient.

\section{Samples and time period}

The total number of women included in the review was 1652 ranging from 123 to 855 women in the individual studies. The populations included healthy pregnant women, however, in two of the studies the women were diagnosed with pelvic girdle pain. ${ }^{5051}$ 


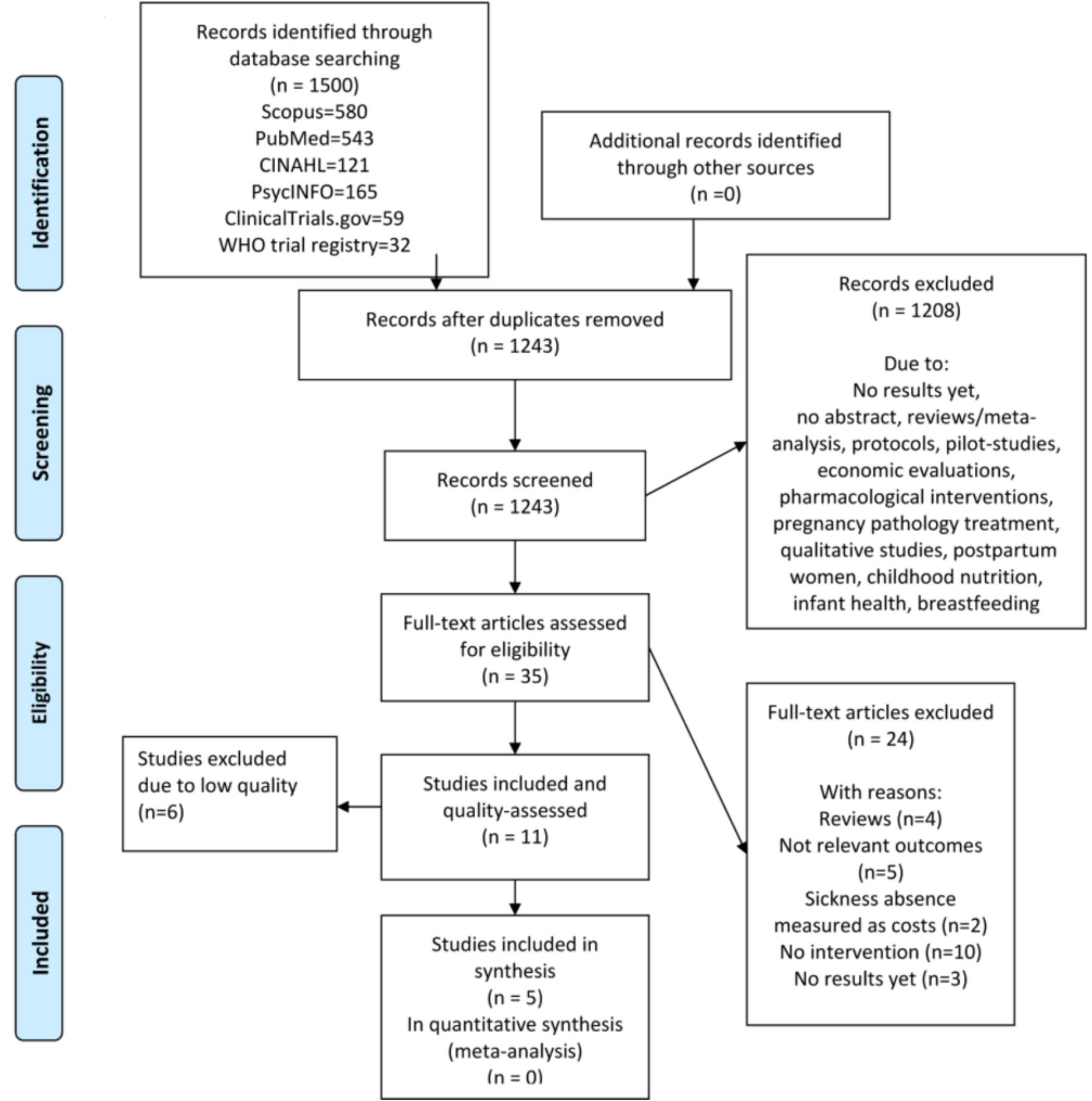

Figure 1 Preferred Reporting Items for Systematic Reviews and Meta-Analyses Flow diagram. Moher et al. ${ }^{49}$

One study was published before $2000,{ }^{52}$ two studies between 2000 and $2010,{ }^{5053}$ and two studies after $2010 .{ }^{5154}$

\section{Interventions}

None of the included studies were performed in a workplace setting. Thus, the included RCTs were all conducted in healthcare settings, that is, antenatal care clinic, physiotherapy clinic or hospital. The providers involved were health professionals, that is, physiotherapists, midwives and general practitioners.

The intervention consisted of physical training in three of the five studies. Kihlstrand et a $\tilde{p}^{2}$ provided physical exercise in water while Mørkved et $a \bar{l}^{\tilde{3}}$ and Stafne $e t a p^{54}$ provided a conventional exercise programme. Two of the interventions applied complementary and alternative medicine: craniosacral therapy and acupuncture treatment, respectively. ${ }^{50} 51$

Kihlstrand et al examined the effect of physical exercise in water compared with no intervention. ${ }^{52}$ The intervention was provided once a week from 17 to 20 weeks of gestational age consisting of $30 \mathrm{~min}$ physical exercise and $30 \mathrm{~min}$ of relaxation. Mørkved et al examined the effect of physical training compared with standard 


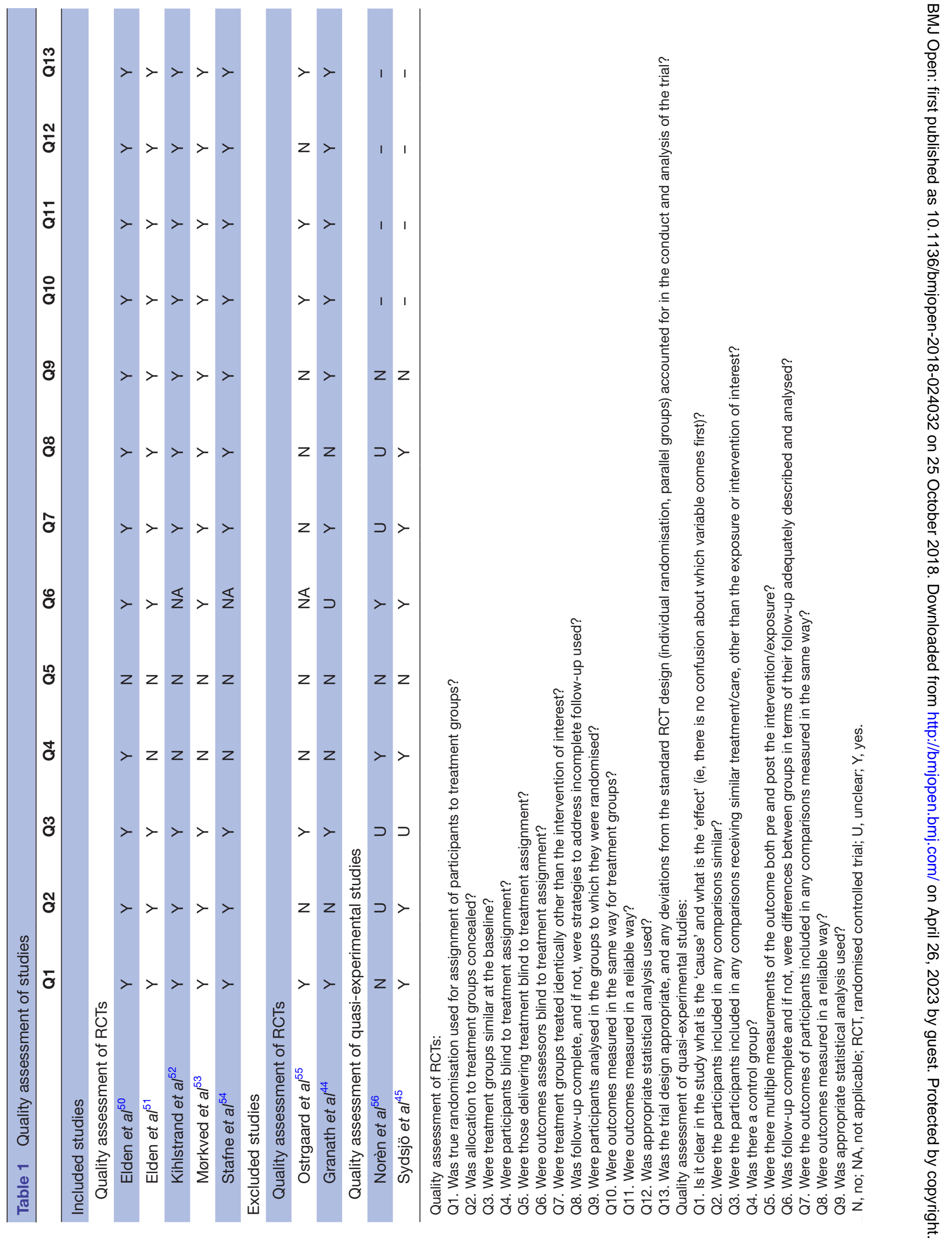




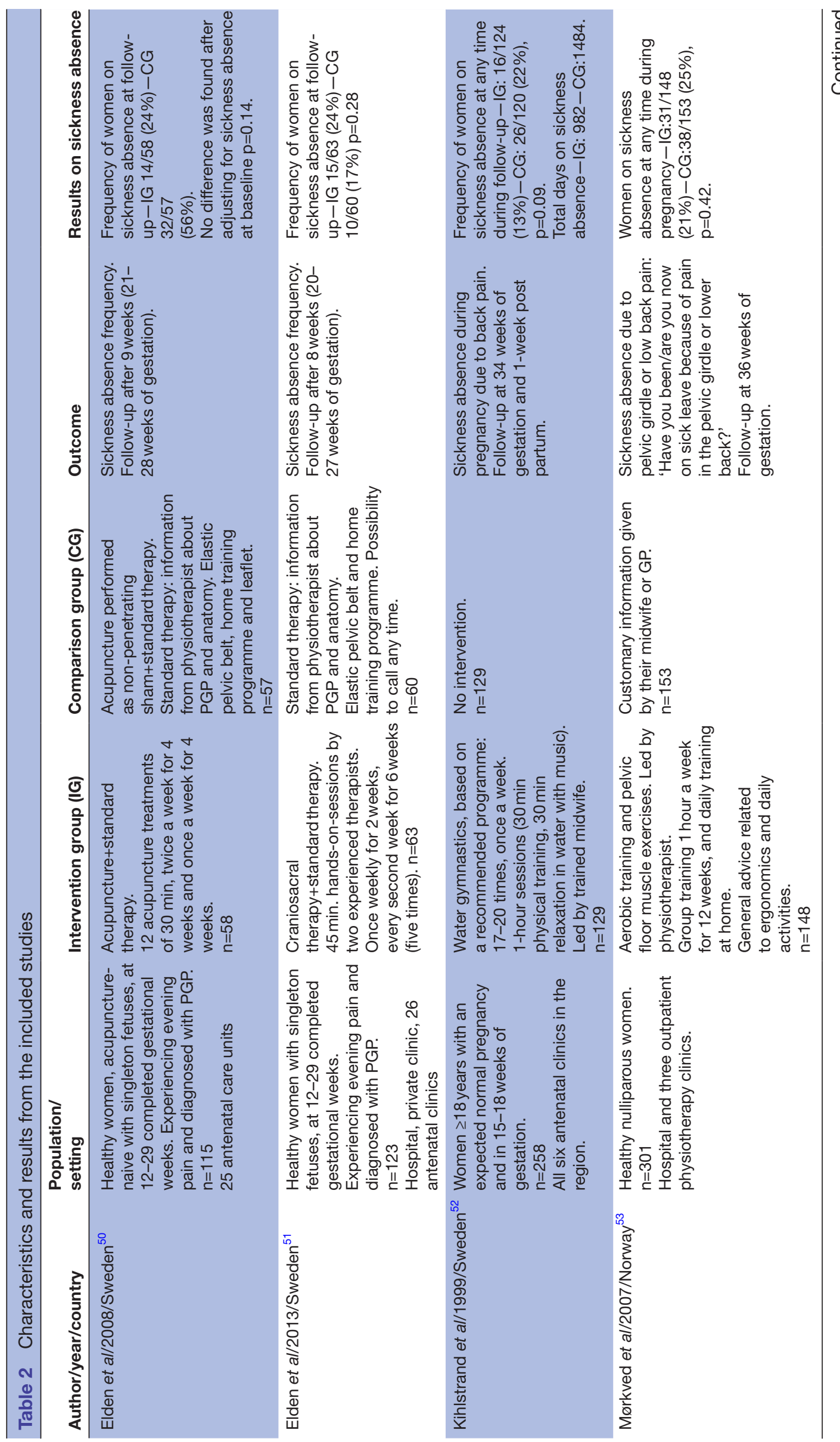




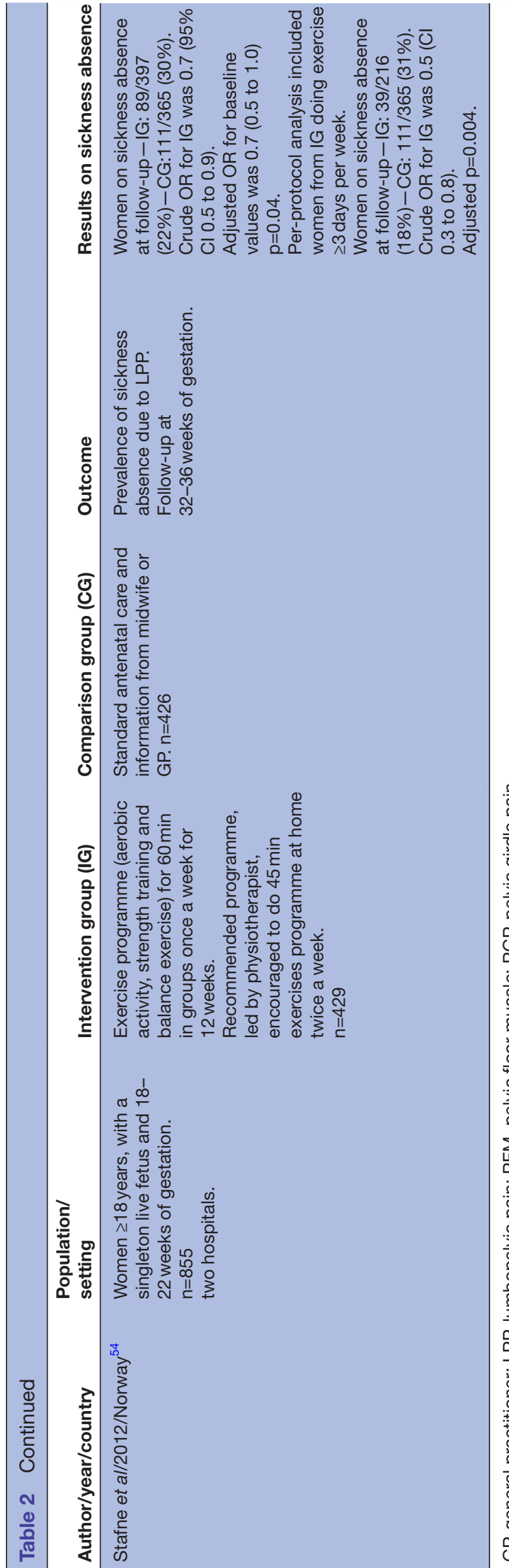

information from midwives and general practitioners. ${ }^{53}$ The programme included 1 hour of aerobic training with a physiotherapist once a week during 12 weeks combined with daily training at home. Stafne et al also examined the effect of exercise compared with standard antenatal care. $^{54}$ The programme consisted of 1-hour aerobic training with a physiotherapist once a week during 12 weeks; the women were also encouraged to do home exercises twice a week.

One study by Elden et al examined the effect of five times craniosacral therapy compared with general information provided by a physiotherapist. ${ }^{51}$ Another study by the same author examined the effect of 12 acupuncture treatment consultations compared with none-penetrating sham acupuncture. ${ }^{50}$

In all studies, the intervention was provided face to face; there was no use of telemedicine, for example, mobile phone or email involved. In three studies, the intervention was group based, ${ }^{52-54}$ otherwise it was individual. ${ }^{5051}$

\section{Outcome measures}

Sickness absence was reported in different ways. Only one RCT reported sickness absence in days, but did not compare the estimates between the groups. ${ }^{52}$ Three RCTs reported the frequency of women on sickness absence at the time of follow-up, ${ }^{50} 51$ whereas two RCTs reported the frequency of women who had been on sickness absence at any time during the pregnancy. ${ }^{52} 53$

Furthermore, overall sickness absence was only measured by Elden et al. ${ }^{51}$ In the three remaining studies, only sickness absence due to back pain, pelvic girdle or low back pain was measured. ${ }^{52-54}$

Sickness absence was measured at different follow-up times: between 20 and 28 weeks of gestation ${ }^{50}$ and in three RCTs between 32 and 36 weeks of gestation. ${ }^{52-54}$

\section{Effectiveness of interventions}

The two studies of complementary and alternative medicine found no differences between the groups. ${ }^{50} 51$ The frequency of sickness absence among pregnant women who received craniosacral therapy at follow-up was $24 \%$ compared with $17 \%$ of those who received general information $(p=0.28),{ }^{51}$ and $24 \%$ among women receiving acupuncture treatment compared with 56\% among women receiving non-penetrating sham acupuncture $(\mathrm{p}=0.14)$, respectively. ${ }^{50}$

Two of the three training interventions demonstrated no effect on sickness absence. A total of $13 \%$ of women participating in physical exercise in water were on sickness absence at follow-up compared with $22 \%$ in the control group $(p=0.09)$. Pregnant women in the intervention group spent 982 days on sickness absence compared with 1484 days in the control group, but no test for difference was calculated. ${ }^{52}$ Two studies examined the effect of physical exercise compared with information from midwives and general practitioners. ${ }^{53}{ }^{54}$ Mørkved et al found a total of $21 \%$ and $25 \%$ had been on sickness absence at any time during pregnancy in the intervention group and the 
control group, respectively $(\mathrm{p}=0.42)$. Stafne et alfound the exercise programme reduced the frequency of women on sickness absence due to low back pain: $22 \%$ in the intervention group versus $30 \%$ in the control group ( $\mathrm{p}=0.04)$, while the frequency was only $18 \%$ among the pregnant women who performed the exercise programme three times a week $(\mathrm{p}=0.004)$.

\section{DISCUSSION}

The aim was to assess the effectiveness of interventions targeting sickness absence; hence the search was limited to experimental studies including a control group. Five RCTs were included in this review, of which all examined interventions delivered in healthcare settings and no intervention was performed at workplaces. Two RCTs examined the effect of complementary and alternative medicine, that is, craniosacral therapy and acupuncture, while three RCTs examined the effect of physical training, that is, exercise in water and a conventional exercise programme.

Conducting a statistical meta-analysis was not possible due to heterogeneity of the interventions. Only a 12-week exercise intervention was able to show a significantly lower frequency of women on sickness absence compared with the control group. ${ }^{54}$ Sickness absence due to low back pain was lower both in the intention-to-treat as well as in the per-protocol analysis, which only included women who had followed the exercise programme minimum three times a week.

Kihlstrand et alfound a difference in number of women on sickness absence at follow-up between groups. ${ }^{52}$ However, the estimate was based on a subgroup analysis with a method not well described. In this review, only the results based on the intention-to-treat analysis were presented, therefore, no effect of the study was reported. Moreover, the study by Elden et al found that more pregnant women were employed in regular work after the intervention compared with participants in the control group. ${ }^{50}$ However, no definition of regular work was stated or how it was measured.

The intention of this review was to measure the occurrence of sickness absence during pregnancy measured as length of sickness absence in days or number of episodes. Only Kihlstrand et al measured sickness absence in days, but did not perform a test of difference between the groups. ${ }^{52}$ All studies analysed the frequency of women on sickness absence, either as a binary outcome at follow-up (yes or no), or sickness absence at any time during the follow-up period. A binary outcome of sickness absence ignores both any information of the length and of previous sickness absence. Therefore, the applied measures may not be suitable to examine a relevant difference between the interventions.

The included studies were based on a sample size calculation detecting a difference in a clinical outcome, that is, pain or diabetes. Measuring an occupational outcome require larger study sample size than measuring clinical outcomes only. ${ }^{57}$ Therefore, the studies may be underpowered and not able to detect a difference in sickness absence. Only the study by Stafne $e t$ al was able to detect a difference in frequency of sickness absence. Notably, this study had the largest sample size of the five studies included. The studies by Elden $e t a \tilde{l}^{50}$ and Kihlstrand et $a \tilde{l}^{2}$ found rather large differences between groups, but the differences were not statistical significantly, which may be due to small study populations.

It is unclear how the studies have examined sickness absence, as a methodological description of the variable and analysis was lacking. Thus, in most of the studies, it was not stated how the question about sickness absence was phrased, and which statistical method was applied. Furthermore, sickness absence was self-reported, which means that the women had to recall sickness absence days and episodes. Self-reported data may not be as sensitive at detecting an episode of sickness absence as register data collected during several months. ${ }^{58}$ However, as the follow-up period in the included studies was between 2 and 4 months, it may only have minor influence on the validity.

Overall, there is little evidence of interventions to reduce sickness absence performed in healthcare settings, and this review found no interventions performed in workplaces, neither among the four excluded studies. However, a newly registered study is aiming to teach managers how to implement a pregnancy policy. ${ }^{59}$

In research on vocational rehabilitation, it is well established that interventions including workplaces are the most effective in reducing the duration of overall sickness absence. ${ }^{5760}$ This may also apply for pregnant women, but more research is needed to confirm that programmes provided in work place settings reduce sick leave frequency during pregnancy.

\section{Strengths and limitations}

This review was based on a systematic search across multiple databases targeting both published and unpublished experimental studies. A quality assessment was performed using a standardised method to ensure only studies of high quality to be included in the review.

Only results based on intention-to-treat and per-protocol analysis in the included studies were included in this review, as subgroup analysis may lead to biased results. ${ }^{61}$

Due to the heterogeneity of the interventions, it was not possible to pool data to perform a statistical meta-analysis. Therefore, the results were only descriptive.

It is a limitation that studies included in this review were only conducted in Sweden and Norway which reduces the representativeness. Therefore, the generalisability of the findings to countries with different labour market and social welfare for pregnant women remains unclear. Another limitation is that none of the studies were provided in workplaces. 


\section{Future recommendations}

It is recommended that future studies in this field will be performed with high quality, for example, power calculation based on sickness absence, transparency of statistical methods and measuring of compliance. First of all, it is important to measure sickness absence based on valid methods, that is, number of days or episodes, and not only as number of individuals on sickness absence. Second, a sample size calculation based on sickness absence should be included. Third, it is highly relevant to test interventions incorporating healthcare settings and the pregnant women's workplaces. Based on this review, we suggest the effect of interventions including physical activity to be further explored.

\section{CONCLUSION}

The evidence of interventions in healthcare settings and workplaces targeting sickness absence among pregnant women is sparse. The five included studies were all provided in Scandinavian healthcare settings without focus on work maintenance, and no studies were provided in workplaces. Only one study showed a significantly lower frequency of pregnant women on sick leave compared with the control group, which was a 12-week exercise programme delivered by a physiotherapist compared with standard antenatal care.

To reduce sickness absence among pregnant women, future interventions including physical activity provided in collaboration with healthcare settings and workplaces are requested. Interventions should measure sickness absence based on valid methods, compliance to the intervention and provide transparency of statistical methods.

\section{Author affiliations}

${ }^{1}$ Central Denmark Region, DEFACTUM - Social and Health Services \& Labour Market, Aarhus, Denmark

${ }^{2}$ Department of Public Health, Section of Clinical Social Medicine and Rehabilitation, Aarhus University, Aarhus, Denmark

${ }^{3}$ Department of Clinical Medicine, Aarhus University, Aarhus, Denmark ${ }^{4}$ Department of Gynaecology Obstetrics, Aarhus Universitetshospital, Aarhus, Denmark

${ }^{5}$ Research Unit for Gynaecology and Obstetrics, Institute of Clinical Research, University of Southern Denmark, Odense, Denmark

Acknowledgements We wish to thank research librarian Helene Sognstrup (Aarhus University Library) for her assistance with the literature search.

Contributors All authors have planned and designed the study. A-MHM and PP conducted the literature search with assistance from a research librarian and reported data for the first draft of the manuscript. CVN, RDM, EAN and ML have critically contributed to revisions of the manuscript. All authors read and approved the final version of manuscript.

Funding The authors have not declared a specific grant for this research from any funding agency in the public, commercial or not-for-profit sectors.

Competing interests None declared.

Patient consent Not required.

Provenance and peer review Not commissioned; externally peer reviewed. Data sharing statement No additional data to the included RCTs.

Open access This is an open access article distributed in accordance with the Creative Commons Attribution Non Commercial (CC BY-NC 4.0) license, which permits others to distribute, remix, adapt, build upon this work non-commercially, and license their derivative works on different terms, provided the original work is properly cited, appropriate credit is given, any changes made indicated, and the use is non-commercial. See: http://creativecommons.org/licenses/by-nc/4.0/.

\section{REFERENCES}

1. Bialobok KM, Monga M. Fatigue and work in pregnancy. Curr Opin Obstet Gynecol 2000;12:497-500.

2. Zib M, Lim L, Walters WA. Symptoms during normal pregnancy: a prospective controlled study. Aust N Z J Obstet Gynaecol 1999;39:401-10.

3. Dørheim SK, Bjorvatn B, Eberhard-Gran M. Insomnia and depressive symptoms in late pregnancy: a population-based study. Behav Sleep Med 2012;10:152-66.

4. Larsson C, Sydsjö A, Alexanderson K, et al. Obstetricians' attitudes and opinions on sickness absence and benefits during pregnancy. Acta Obstet Gynecol Scand 2006;85:165-70.

5. Fredriksen EH, Harris J, Moland KM, et al. "They ask whether this is real or fake": a qualitative norwegian study of pregnancy complaints and access to social benefits. Health Care Women Int 2014;35:266-84.

6. Tophøj A. [Assessment of occupational environment of pregnant women by general practitioners and specialists in occupational medicine]. Ugeskr Laeger 1999;161:5019-23.

7. Kaerlev L, Jacobsen LB, Olsen J, et al. Long-term sick leave and its risk factors during pregnancy among Danish hospital employees. Scand J Public Health 2004;32:111-7.

8. Alexanderson K, Sydsjö A, Hensing G, et al. Impact of pregnancy on gender differences in sickness absence. Scand J Soc Med 1996;24:169-76.

9. Angelov N, Johansson P, Lindahl E. Gender differences in sickness absence and the gender division of family responsibilities. Working Paper. Upsala, Sweden: The Institute for Evaluation of Labour Market and Education Policy (IFAU), 2013;9.

10. Ariansen AM, Mykletun A. Does postponement of first pregnancy increase gender differences in sickness absence? A register based analysis of Norwegian employees in 1993-2007. PLoS One 2014;9:e93006.

11. Myklebø S, Thune O. Sickness absence among pregnant women. [Sykefravær blant gravide] Work and wellfare 2010;2:54-9.

12. Sydsjö A, Sydsjö G, Alexanderson K. Influence of pregnancy-related diagnoses on sick-leave data in women aged 16-44. J Womens Health Gend Based Med 2001;10:707-14.

13. Thorsen SV, Flyvholm M, Bültmann U, et al. Descriptive analysis of employees'sickness absence in Danmark - based on data from registries and surveys [Deskriptiv analyse af lønmodtagerenes sygefravær i Danmark - belyst ud fra register- og spørgesksemadata fortrinsvis fra 2010-2014]: National Research Centre for the Working Environment, 2016.

14. The Ministry of Employment [Beskæftigelsesministeriet]. Analysis of pregnancy-related absence [Analyse af graviditetsbetinget fravær]. Copenhagen, Denmark: The Ministry of Employment, 2010.

15. Dørheim SK, Bjorvatn B, Eberhard-Gran M. Sick leave during pregnancy: a longitudinal study of rates and risk factors in a Norwegian population. BJOG 2013;120:521-30.

16. Rieck KME, Telle K. Sick leave before, during and after pregnancy. Acta Sociologica 2013;56:117-37.

17. Markussen S, Røgeberg O. Sickness absence during life events. [Sykefravær rundt større livshendelser. The Journal of the Norwegian Medical Association 2012;132:1231-4.

18. Sydsjö A, Sydsjö G, Wijma B, et al. Changes in sick leave rates and the use of pregnancy-associated social benefits among pregnant Swedish women: an outcomes study. J Womens Health 1998;7:249-60.

19. Sydsjö A, Sydsjö G, Kjessler B. Sick leave and social benefits during pregnancy-a Swedish-Norwegian comparison. Acta Obstet Gynecol Scand 1997;76:748-54.

20. Sydsjö A, Alexanderson K, Dastserri M, et al. Gender differences in sick leave related to back pain diagnoses: influence of pregnancy. Spine 2003;28:385-9.

21. Tophøj A, Mortensen JT. [Pregnancy-related and work-related sick leave of pregnant women]. Ugeskr Laeger 1999;161:5009-13.

22. Liddle SD, Pennick V. Interventions for preventing and treating lowback and pelvic pain during pregnancy. The Cochrane Library 2015.

23. Norén L, Ostgaard S, Johansson G, et al. Lumbar back and posterior pelvic pain during pregnancy: a 3-year follow-up. Eur Spine $J$ 2002;11:267-71. 
24. Hansen ML, Thulstrup AM, Juhl M, et al. Predictors of sickness absence in pregnancy: a Danish cohort study. Scand J Work Environ Health 2015;41:184-93.

25. Hansen ML. Sickleave in pregnancy - risk factors and prognosis. Studies among Danishemployed women.[dissertation. Denmark: HealthAarhus University, Danish Ramazzini Centre, Department ofOccupational Medicine Aarhus University Hospital, 2016.

26. Ariansen AMS. Age, occupational class and sickness absence during pregnancy: a retrospective analysis study of the Norwegian population registry. BMJ Open 2014;4-e004381-004381.

27. Brekke I, Berg JE, Sletner L, et al. Doctor-certified sickness absence in first and second trimesters of pregnancy among native and immigrant women in Norway. Scand J Public Health 2013;41:166-73.

28. Kristensen P, Nordhagen R, Wergeland E, et al. Job adjustment and absence from work in mid-pregnancy in the Norwegian Mother and Child Cohort Study (MoBa). Occup Environ Med 2008;65:560-6.

29. Palmer KT, Bonzini M, Bonde JP. Pregnancy: occupational aspects of management: concise guidance. Clin Med 2013;13:75-9.

30. Hansen ML, Thulstrup AM, Juhl M, et al. Occupational exposures and sick leave during pregnancy: results from a Danish cohort study. Scand J Work Environ Health 2015;41:397-406.

31. Bonde JP, Jørgensen KT, Bonzini M, et al. Miscarriage and occupational activity: a systematic review and meta-analysis regarding shift work, working hours, lifting, standing, and physical workload. Scand J Work Environ Health 2013;39:325-34.

32. Palmer KT, Bonzini M, Harris EC, et al. Work activities and risk of prematurity, low birth weight and pre-eclampsia: an updated review with meta-analysis. Occup Environ Med 2013;70:213-22.

33. Salihu HM, Myers J, August EM, et al. Pregnancy in the workplace. In-depth review. Occup Med 2012;62:88-97.

34. Strand K, Wergeland E, Bjerkedal T. Job adjustment as a means to reduce sickness absence during pregnancy. Scand J Work Environ Health 1997;23:378-84.

35. Schaumburg I. Benefits during pregnancy due to risk of teratogenicity in the work environment. [Dagpenge i graviditeten på grund af risiko for fosterskade i arbejdsmiljøet]. Danish Medical Bulletin 1986;148:918-20.

36. Sydsjo G, Sydsjo A. Newly delivered women's evaluation of personal health status and attitudes towards sickness absence and social benefits. Acta Obstet Gynecol Scand 2002;81:104-11.

37. Sydsjö G, Sydsjö A, Wijma B. Variations in sickness absence and use of social benefits among pregnant women in a Swedish community 1978-1997. Acta Obstet Gynecol Scand 1999;78:383-7.

38. Tophoj A. Pregnancy and sick leave. Danish Medical Bulletin 1994;156:6359-65.

39. Fredriksen EH, Moland KM, Sundby J. "Listen to your body": a qualitative text analysis of internet discussions related to pregnancy health and pelvic girdle pain in pregnancy. Patient Educ Couns 2008;73:294-9.

40. Scheil-Adlung X, Sandner L. The case for paid sick leave. World health report 2010

41. Dorheim SK, Eberhard-Gran M. What is the right level of sick leave among pregnant women? Womens Health 2013;9:125-6.

42. WHO Recommended Interventions for Improving Maternal and Newborn Health. Geneva, Switzerland: WHO, 2009. Report No.: WHO/MPS/07.05.
43. van Beukering MDM, et al. Practice guideline pregnancy, postpartum period and work Advice and guidance by the occupational physician. Utrecht, Netherlands: NVAB, the Netherlands Society of Occupational Medicine, 2007.

44. Granath AB, Hellgren MS, Gunnarsson RK. Water aerobics reduces sick leave due to low back pain during pregnancy. J Obstet Gynecol Neonatal Nurs 2006;35:465-71.

45. Sydsjö G, Monfils WG, de Keyser N, et al. Effects of a weight-gain restriction programme for obese pregnant women on sickness absence and pregnancy benefits. Scand J Prim Health Care 2013;31:106-10.

46. Joanna Briggs Institute - JBI. http://joannabriggs.org/

47. Hensing G, Alexanderson K, Allebeck P, et al. How to measure sickness absence? Literature review and suggestion of five basic measures. Scand J Soc Med 1998:26:133-44.

48. Joanna Briggs Institute. JBI SUMARI. 2017. https://www.jbisumari. org/

49. Moher D, Liberati A, Tetzlaff J, et al. Preferred reporting items for systematic reviews and meta-analyses: the PRISMA statement. J Clin Epidemiol 2009;62:1006-12.

50. Elden H, Fagevik-Olsen M, Ostgaard HC, et al. Acupuncture as an adjunct to standard treatment for pelvic girdle pain in pregnant women: randomised double-blinded controlled trial comparing acupuncture with non-penetrating sham acupuncture. BJOG 2008;115:1655-68.

51. Elden $\mathrm{H}$, Östgaard $\mathrm{H}-\mathrm{C}$, Glantz $\mathrm{A}$, et al. Effects of craniosacral therapy as adjunct to standard treatment for pelvic girdle pain in pregnant women: a multicenter, single blind, randomized controlled trial. Acta Obstet Gynecol Scand 2013;92:775-82.

52. Kihlstrand M, Stenman B, Nilsson S, et al. Water-gymnastics reduced the intensity of back/low back pain in pregnant women. Acta Obstet Gynecol Scand 1999;78:180-5.

53. Mørkved S, Salvesen KA, Schei B, et al. Does group training during pregnancy prevent lumbopelvic pain? A randomized clinical trial. Aust J Physiother 2007;86:276-82.

54. Stafne SN, Salvesen KA, Romundstad PR, et al. Regular exercise during pregnancy to prevent gestational diabetes: a randomized controlled trial. Obstet Gynecol 2012;119:29-36.

55. Ostgaard HC, Zetherström G, Roos-Hansson E, et al. Reduction of back and posterior pelvic pain in pregnancy. Spine 1994;19:894-900.

56. Norén L, Ostgaard S, Nielsen TF, et al. Reduction of sick leave for lumbar back and posterior pelvic pain in pregnancy. Spine 1997;22:2157-60.

57. Nieuwenhuijsen K, Faber B, Verbeek JH, et al. Interventions to improve return to work in depressed people. Cochrane Database Syst Rev 2014;1212:CD006237.

58. van Poppel MNM, et al. Measuring sick leave: a comparison of selfreported data on sick leave and data from company records. Occup Med 2002;52:485-90.

59. Active Pregnancy Policy at Work, 2016. Greater wellbeing and lower sickness absence https://clinicaltrials.gov/ct2/show/NCT03002987.

60. Arends I, Bruinvels DJ, Rebergen DS, et al. Interventions to facilitate return to work in adults with adjustment disorders. Cochrane Database Syst Rev 2012;12:CD006389.

61. Freemantle N. Interpreting the results of secondary end points and subgroup analyses in clinical trials: should we lock the crazy aunt in the attic? BMJ 2001;322:989-91. 